\title{
Ethnomethodologically Informed Ethnography and Information System Design
}

\author{
Andy Crabtree, Sociology Department, Lancaster University, Lancaster LA1 4YL, UK. E-mail \\ a.crabtree@lancaster.ac.uk
}

David M. Nichols, Computing Department, Lancaster University, Lancaster LA1 4YR, UK. E-mail: dmn@comp.lancs.ac.uk

Jon O’Brien, Xerox Research Centre Europe, Cambridge Laboratory, 61 Regent Street, Cambridge, CB2 1AB, UK. E-mail: jon.obrien@xrce.xerox.com

Mark Rouncefield, Computing Department, Lancaster University, Lancaster LA1 4YR, UK. E-mail: m.rouncefield@lancs.ac.uk

Michael B. Twidale, Graduate School of Library and Information Science, University of Illinois at UrbanaChampaign, IL 61820, USA. E-mail: twidale@alexia.lis.uiuc.edu

\begin{abstract}
The paper describes ethnomethodologically informed ethnography (EM) as a methodology for information science research, illustrating the approach with the results of a study in a university library. We elucidate major differences between the practical orientation of EM and theoretical orientation of other ethnographic approaches in information science research. We address ways in which EM may be used to inform systems design and consider the issues that arise in co-ordinating the results of this research with the needs of information systems designers. We outline our approach to the 'ethnographically informed' development of information systems in addressing some of the major problems of interdisciplinary work between system designers and EM researchers.
\end{abstract}

\section{Introduction}

Within the field of Library and Information Science (LIS) there is a concern with the development of information technologies supporting the browsing, searching, and retrieving of information in library contexts. To this end, questionnaire surveys, observations andinterviews with library users, case studies, protocol analysis, transaction log analysis of online catalogues, and more, have been used in conjunction with cognitive theory and the matching model as

(C) John Wiley \& Sons Inc., 2000. This is the author's version of the work. It is posted here for your personal use. Not for Redistribution. The definitive version was published in the Journal of the American Society for Information Science, vol. 51 (7), pp. 666-682. the primary means of developing an understanding of how users 'go about' producing information of relevance. Although modest technological advances have been achieved, expectations have yet to be fully realised (Borgman, 1996) and critics in the field suggest that the enterprise needs to develop means of understanding user behaviour that take better account of the 'reality' of the information retrieval situation (Bates, 1989; Frohmann, 1992; Lamont, 1995).

One means of addressing this issue has been to turn to ethnography (Kuhlthau, 1993; Mellon, 1990; Nardi \& O’Day, 1996; O’Day \& Jeffries, 1993; Sandstrom \& Sandstrom, 1995; Squires, 1997; Zeitlyn et al., 1997). Solomon's recent treatment of the construction of sense and production of information (Solomon, 1997 ${ }^{\mathrm{a}}, 1997^{\mathrm{b}}, 1997^{\mathrm{c}}$ ) epitomises the ways in which such studies have been conducted and ethnographic findings treated within the field. In reporting on the construction of sense and production (and use) of information in a work planning process, Solomon elucidates what are taken by many to be central tenets of ethnographic method, not only in LIS but across the broad spectrum of the social sciences.

By way of contrast, this paper aims to describe ethnomethodologically informed ethnography (EM), as an alternate ethnographic method for information science research, and to describe how the results of such research can be understood and applied by designers of information systems. This involves the explication of EM research, its 
rationale, illustrations of its production and use, and its relationship to other ethnographic approaches. We also describe how this form of ethnography can be used to inform the systems design process, addressing in a formative manner the problems of interdisciplinary work.

The paper is structured in terms of four interrelated strands. The first strand explores ethnographic research in general and treats major problems implicated in undertaking such work. Strand two explicates the notion of ethnomethodologically informed ethnography (EM), its intellectual foundations, and practical issues in undertaking an EM study. In strand three we present a series of short studies undertaken in a university library in order to illustrate the practicalities of EM research. Strand four explores the difficulties in making use of ethnographic findings in doing the job of design and describes the practical strategies we have devised to address the problem. Of particular interest here are the practical troubles occasioned in the accomplishment of interdisciplinary work. ${ }^{1}$

\section{Strand One: What is ethnography?}

Originally developed out of the 'strange tales of faraway places' of early Social Anthropology and adapted for sociological employ through the 'naturalistic stance' of the Chicago School and Symbolic Interactionism, ethnography's concern is 'to balance detailed documentation of events with insights into the meaning of those events' (Fielding, 1994: 154).

Despite this apparently unitary policy, as we will argue in some detail below, ethnography is not in any sense a unitary method - if indeed the word method is applicable at all to its many and varied practices - but an umbrella term for various and different analytic frameworks. It is here that a good deal of confusion arises with regard to just what it means to do ethnography. While an ethnographic stance in general arguably entails a minimum orientation towards seeing the social world from the point of view of participants, one particular approach to this, which has strongly influenced our own work, is the ethnomethodological one, in which members' reasoning and methods for accomplishing situations becomes the topic of enquiry. We shall expand upon this orientation and its distinction from other analytic frames within which ethnographic techniques are cast throughout the course of the paper.

\section{Ethnography for Systems Design}

Efforts to incorporate ethnography into the systems development process have stemmed from the realisation, mainly among systems designers, that the success of design has much to do with the social context into which systems are placed. Systems are used within peopled environments which are, whatever technological characteristics they may have, social in character. Ethnography, with its emphasis on the in situ observation of interactions within their natural settings, seemed to lend itself to bringing a social perspective to bear on system design.

The main virtue of ethnography lies in its ability to make visible the real-world sociality of a setting. ${ }^{2}$ As a mode of social research it is concerned to produce detailed descriptions of the 'workaday' activities of social actors within specific contexts. It is a naturalistic method in that it relies upon material drawn from the first-hand experience of a fieldworker in some setting and seeks to present a portrait of life as seen and understood by those who live and work within the domain concerned. This objective elucidates the rationale behind the method's insistence on the development of an 'appreciative stance' through the direct involvement of the researcher in the setting under investigation. It is, as Fielding (1994) suggests:

\footnotetext{
'.. a stance which emphasise[s] seeing things from the perspective of those studied before stepping back to make a more detached assessment. ... mindful of the Native American adage that one should "never criticise a man until you have walked a mile in his moccasins.' (Fielding, 1994: 156)
}

In summary, the advantage of applying ethnographic 'methods' lies in the 'sensitising' they promote to the real-world character of activities in context and, consequently, in the opportunity to ensure system development resonates with the circumstances of systems use. In attempting not only to document or describe activities but to explicate (or make observable) their real-world organisation, ethnography seeks to answer what might be regarded as an essential question in design: what to automate and 
what to leave to human skill, competence, judgement, experience and expertise.

\section{Doing ethnography: practicalities and analytic orientations}

As noted above, it is not at all uncommon to see ethnographic approaches employed in LIS research, approaches marked by the immersion of a fieldworker within a library setting, gaining an insiders' familiarity with, and gathering descriptions of, given areas of activity. In this regard our approach is in no way different: we are faced with the practicalities of gathering data about the fieldsetting and its constituent phenomena, and typically produce dense textual descriptions and sketched outlines of the ecology of the workplace and the activities which constitute the work within it. Where permission is given, the ordinary flow of conversation and workplace chat is recorded and transcribed at a later date, forming an important part of the ethnographic record: the assembled and analysed findings of the study. Field notes and audio recordings are accompanied, where appropriate, by the use of video and still photography, which, in combination with textual description, set out to convey a sense of the real-world, real-time nature of the work as it actually takes place, rather than some idealised version of events (Rouncefield et al., 1994).

To anyone but the researcher, field descriptions - the 'stuff' of the ethnographic record - have a tendency to appear idiosyncratic, messy and confusing at first glance. Some kind of order needs to be brought to bear whereby the record can be organised and findings extracted and made publicly and professionally intelligible. The extraction of findings from the record is called 'analysis' and as Solomon points out:

\footnotetext{
'A key aspect of the analysis process [is] the development of a classification scheme for coding of [the] data.' (Solomon, 1997 ${ }^{\mathrm{a}}$ : 1102)
}

It is at this analytic level that the EM research approach we favour breaks in a fundamental, foundational sense from the vast majority of LIS and other social scientific approaches to ethnographic study. Our concern does not lie with the doing of the ethnographic study as such, but with what is done with the findings of that study. As we will explicate in detail below, we reject the notion that the findings of such study should be 'slotted into' debates as evidence for or against certain theoretical frameworks, leading to the rejection or reformulation of these theories or the construction of new 'improved' theories.

It is precisely in this context - that of the theoretically-oriented use to which the findings of ethnographic studies are put - that confusions tend to arise when considering just what ethnography is, and what it is for. As Shapiro (1994) reminds us, the term 'ethnography' denotes little more than a distinction between quantitative and qualitative research in itself. As such 'ethnography can be put to the service of virtually any theoretical school: there are for example functionalist, structuralist, interactionist, Weberian and Marxist ethnographies' (Shapiro, 1994: 418) and as even the most cursory glance at LIS literature makes clear, ethnography has indeed been put to the service of multiplicity of theoretical schools within the field. This is not the place to explore the differences between the various schools of thought at work in LIS. It is, however, to note that 'ethnography' is anything but a unified method, indeed it is not really a method at all but, as Shapiro points out, rather a term that collects together various and different analytic frameworks under the rubric of qualitative methodology. One of our key concerns in this paper is to delineate the distinct position of the EM research approach in this regard.

\section{Theoretical Frameworks, Codification and Analysis}

A consideration of Solomon's (1997a, $1997 b, 1997 \mathrm{c})$ ethnographic work illustrates our concerns with much of the analysis to which ethnographic material is subjected, as a means of producing some kind of intelligible 'tale' from the raw findings. Though an ad hoc procedure developed 'on the run', the method of classification Solomon employs in order to conduct analysis is anything but idiosyncratic, being common practice in social research. It consists of following coding instructions providing for the application of pre-formulated classification categories. Coding instructions do not apply themselves and the codification of data through the application of a classification scheme's categories relies on the discretionary exercise of judgement in-theface of the local events the schema's categories are intended to analyse (Garfinkel, 
1967). Solomon elected to apply Elion's (1968) taxonomy of communicative events and Dervin's (1992) sense-making framework of 'situations', 'gaps' and 'uses' to the data, for example, in conjunction with an ad hoc framework developed in the course of the research for dealing with other witnessed local events.

The point and purpose of codification and classification is to make the social (or psychological) organisation of the setting visible:

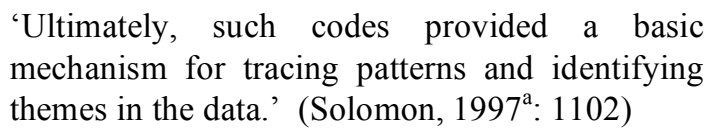

'Ultimately, such codes provided a basic mechanism for tracing patterns and identifying themes in the data.' (Solomon, 1997 ${ }^{\mathrm{a}}$ : 1102)

In tracing patterns and identifying themes, the social organisation of the setting is rendered apparent. Again, this is not idiosyncratic behaviour but bona fide social scientific practice.

The practical problem of tracing patterns and identifying themes, and understanding them rigorously (or scientifically), is resolved through the use of the documentary method. The documentary method is employed to establish a correspondence between actual witnessed appearances and underlying patterns. Its use consists of:

\footnotetext{
" ... treating an actual appearance as "the document of", as "pointing to", as "standing on behalf of" a presupposed underlying pattern. Not only is the underlying pattern derived from its individual documentary evidences, but the individual documentary evidences, in their turn, are interpreted on the basis of "what is known" about the underlying pattern. Each is used to elaborate the other.' (Garfinkel, 1967: 78)
}

The layman interprets documentary evidences on the basis of his or her common sense knowledge of society; on the basis of 'what anybody knows'. The social scientist (or cognitive scientist or information scientist etc.) interprets documentary evidences on the basis of the corpus of disciplinary and interdisciplinary knowledge. Thus, in addition to Dervin (1992), Solomon employs Weick's (1995) master narrative (theory) on sensemaking in organisations; Hymes' (1986) framework for analysing communicative events; Giddens' (1984) account of structuration; and Kuhlthau's (1993) master narrative on cognitive processes. Individual documentary evidences are interpreted - and patterns thereby traced and themes identified through the use of concepts derived from predefined analytic frameworks. For example:
'Hymes analytical framework highlights key elements in a communicative event ... It provides a facetted framework for identifying patterns of behaviour within and among communicative events as well as highlights those factors that need to be considered in analysis.' (Solomon, 1997 : 1115)

The work of analysis is completed and made professionally intelligible and of objective status through the embedding of findings in the master narratives the corpus of disciplinary and inter-disciplinary knowledge consists of (Livingstone, 1997). Thus, a rigorous, scientific understanding of social organisation of information production is achieved and made available to design through the use of:
․ Ethnographic descriptions
口 Coding instructions
- Non-indigenous taxonomies and classification schemes
- The documentary method of interpretation
- Pre-defined analytic frameworks
- Master narratives (or grand theories)

These are the orthodox or conventional practices in and through which much social science qualitatively treats and thereby makes sense of (comes to understand and otherwise explain) the sociality of information production. These practices consist of treating witnessed appearances through the application of pre-defined rules and procedures of interpretation vis-à-vis abstraction conceived to provide for rigor, scientific status and the generalisation of findings, ceteris paribus applying. ${ }^{3}$

As practising ethnographers we disagree with the orthodoxy outlined here. Our disagreement is not based on some alternative theoretical basis but on methodological concerns. The understanding or knowledge of human conduct generated by orthodox machinery is the product of the ethnographer's situated accomplishment of the practices of social science. ${ }^{4}$ What we see, then, is not how the setting's daily work is organised from the point of view of parties to it but how that work is organised from the point of view the analyst (Zimmerman \& Wieder, 1973). The orthodox practices in and through which the record is treated we refer to as the practices of 'constructive analysis'.

The problem of constructive analysis 
It might be thought that the (putatively) scientific and professional character of constructive analysis warrants persistence with the approach. As Solomon puts it:

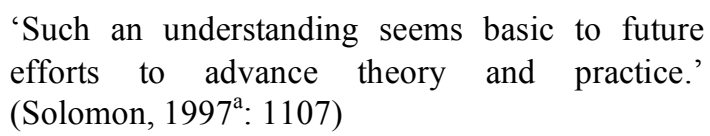

'Such an understanding seems basic to future efforts to advance theory and practice.' (Solomon, 1997ª 1107)

Following Garfinkel, we are not convinced by such intellectual promise. The issue of codification serves to elucidate the nature of our objection. As Garfinkel (1967) points out, coded results are treated as 'disinterested descriptions' of witnessed events. The disinterested or objective character of coded results - which is the actual material of constructive analysis qua analysis, in contrast to the ethnographic record itself - is seen to be provided by the coding instructions. Coding instructions are treated as scientific procedures which, in their application, provide for the rigorous description of the social organisation of the setting's activities. Insofar as the ethnographic record is a product of that organisation on any occasion of inquiry and in so much as the coding instructions are applied to that record, then the coded results are taken to be a part of the actual social organisation they purport to describe - the work of making sense of artefacts in the library and producing information, say. Thus, coded results make visible the social organisation of the setting.

As Garfinkel describes it, in treating the ethnographic record in this way, conventional social science treats coded results

\footnotetext{
'... in much the same way that one might treat a person's report on his own activities as a feature of his activities.' (Garfinkel, 1967: 24)
}

Such a report does not describe the activities of which it is a feature however; the activities themselves remain to be described. Therein lies the reason for our scepticism regarding the promise of constructive analysis. Coded results are akin to a person's report on his or her activities and as such the activities and practices the coded results emerge from remain to be described. A fortiori, under the auspices of constructive analysis, the social practices in and through which members make sense of artefacts and produce information of relevance have not yet been described. Furthermore: the methodology of constructive analysis denies the technology development effort any prospect of discovering those practices.
That prospect is denied in that constructive analysis' practices have been designed to satisfy criteria of scientific rigour incongruent with the subject matter of the social sciences (Hughes \& Sharrock, 1997; Button, 1991; Garfinkel, 1967; Blumer, 1969; Winch, 1958; Dilthey, 1988). The phenomena we see, and thus the understanding we generate through the practices of constructive analysis, are the products of those practices not of the practices constitutive of the phenomena itself. As such, the practices of constructive analysis can do no other than pass members practices by. 5

Before proceeding further, it should be said that insofar as we have used Solomon's work to elucidate this point then it is not towards the end of criticising that work. We are not interested in criticising Solomon's work, it is work of the first order, hence our selection of it as our choice of example. What we want or hope to achieve by explicating the ethnographic practices engaged in by Solomon - i.e. the practices advocated by the conventional social sciences which Solomon has so craftfully and competently performed is to point out the limitations of those practices. Specifically, that in the performance of the practices of constructive analysis, the real-world practices in and through which members make sense of settings, activities, artefacts, and events, and thus come to produce information, are glossed over and obscured. Constructive analysis cannot do otherwise. ${ }^{6}$

\section{Strand Two: The orderly accomplishment of structure and process}

In and through doing the work of glossing members' real-world practices - i.e. in doing coding, interpreting, analysing and embedding results - information production comes to be conceived in terms of underlying structural and cognitive procedures and processes. ${ }^{7}$ As Suchman (1983) points out, the procedural structure of activities is the product of the orderly work of parties to their accomplishment, rather than the reflection of some enduring structure that stands behind that work. Thus, as Hughes et al. (1994) point out, it is through the social practices whereby the setting's activities 'get done', that structure and process emerge. We take ethnography's task to be one of explicating and making available to design the embodied (real-world) social practices in and through 
which structure and process emerge. The methodological question is: how might we 'go about' doing that?

Doing-coding-results glosses over the realworld practices whereby people structure the making of sense of artefacts, activities, events, etc., and (thus) come to produce information in a processual fashion. As such, Garfinkel suggests that

\footnotetext{
'Coding instructions ought to be read instead as a grammar of rhetoric; they furnish a "social science" with a way of talking so as to persuade consensus and action.' (Garfinkel, 1967: 24)
}

Recognising the limitations social science grammars of rhetoric place on the ethnographic record, we advocate that the methodological policies of constructive analysis be abandoned in the effort to achieve a rigorous understanding of the real-world practices implicated in the production of information and the subsequent development of appropriate technological support.

As noted earlier, ethnography is a gloss on various and different analytical frameworks and EM is one such analytic framework. It is, however, a radically alternate one. The alternate character of EM is to be found in its unique policies and practices. In the first instance, EM is a determinedly 'unconstructive' enterprise - it rejects the practices of coding and classifying the ethnographic record through the instructed application of pre-defined taxonomies and analytic frameworks, and rejects any attempt to achieve a rigorous understanding of social organisation through the construction of master narratives or models explaining the real-world. ${ }^{8}$

Ethnomethodology refuses to theorise practice in that, and precisely because, members' real-world practices are only discoverable. In no way are they imaginable. Ethnomethodology offers no theories then, it does not build theories and does not build them because it has no work for them to do: social practice $q u a$ practice in real-time cannot be discovered through such Rational practices of the imagination. EM instead places methodological emphasis on the rigorous description of the situated (i.e. local, observable) actions and practices (Suchman, 1987) in and through the contingent accomplishment of which a settings' activities are produced and re-produced by its staff. Thus, in the first instance, EM's findings should not be read as theories but as 'thick' descriptions (Ryle, 1971; Sharrock \& Button, 1991). That is, as descriptions which make observable the embodied actions and practices in and through which members, alone and in concert, produce a concrete sense of 'just what' they are doing, and 'just how', thereby accomplishing the daily activities of the setting: browsing, searching, finding and retrieving information in libraries, say.

The methodological issue of course is how we 'go about' producing thick descriptions. What are EM's practices of producing factual knowledge of a calculable status regarding a setting's social organisation? It is to a consideration of this issue that we now turn our attention.

\section{Ethnomethodology: discovering social practice}

In keeping with the ethnographic tradition we 'go about' producing descriptions of members' practices by adopting the naturalistic stance. We seek to portray the practices in and through which members organise, produce and accomplish the daily activities of a setting from the point of view of parties to the setting's daily work. By 'point of view' we do not refer to any individual's personal perspective on the work however, but to their performance of the work within an embodied organisation of activities. Thus, we seek to describe the 'lived production' of the work - the actions and practices in and through which the work 'gets done' time and time again by any competent member and which we believe good design should, therefore, seek to support.

This does not mean that we believe the technology development effort ought to reproduce in one-to-one detail the practices in and through which a setting's work 'gets done'. In details of performance those practices may well be constrained by the contingent design of current technologies and artefacts of work. New technology clearly offers members the opportunity to accomplish the daily work of a setting in a more efficient, easy and prospectively different manner, transforming the work and working relations in its implementation. In order to bring about such a state of affairs however, it is necessary to understand what 'getting the job done' actually entails. To understand the practised ways in which members make sense of everyday contingencies? How they make such contingencies routine accomplishments of work? How they interweave or coordinate 
their activities? What local knowledge and small constellations of assistance enable the accomplishment of the work?

In order to address these issues, when we approach the job of description we ask and seek to explicate in indigenous 'happening' detail what is being done and by whom, how is it being done and done again, and why is it being done in the ways that it visibly is. Particular attention is paid to the embodied inter-actions and practices 'within' which current technologies and artefacts are embedded. This focus on the technology-inuse (Button, 1992) provides for the identification of realistic possibilities for design, for the elaboration of concrete designproblems, and for the formulation of potential design-solutions.

Insofar as we are concerned with explicating the enacted practices people engage in, in order to get the work of the setting done, then we do not impose prespecified procedures on the work of description. Thus, we do not 'hypothesise' the research problem; we do not 'operationalise' theoretical constructs; we do not formulate 'classification schemes'; we do not engage in 'representative sampling', and so on (Bradley, 1993). In other words, we do not pre-figure the research but instead let the phenomena drive it.

In order to perform the work of analysis, the researcher needs to assemble coherent and concrete cases or instances of the discrete activities the daily work of the setting consists of (Blomberg et al., 1994; Crabtree, 1998). These concrete cases should preserve and display the lived details of the work. Thus, performed activity as described in the 'instance' is the direct unit of analysis, instead of coded results.

Having assembled a concrete case of a performed activity describing the lived details of that activity's work, the work of analysis proper may be undertaken. In conducting analysis in an ethnomethodological mode, the researcher is not looking for patterns but the social practices in and through which patterns (like structures and processes) emerge. Thus, analysis does not proceed through the application of pre-defined analytical frameworks to the case-at-hand. Nor does analysis proceed through the construction of hypotheses as 'suggested by' the data and the subsequent attempt to demonstrate support for those hypotheses (Bogdan \& Taylor, 1975; Packer \& Addison, 1989; Tesch, 1990).
Analysis in an ethnomethodological mode is not in the business of making suggestions in that and precisely because the making of suggestions relies on the documentary method of interpretation.

Eschewing the practices of constructive analysis, analysis in the ethnomethodological mode proceeds through the faithful description of the social practices (or members' methods) in and through which the witnessed activity was observably produced and achieved. As Benson \& Hughes describe the matter:

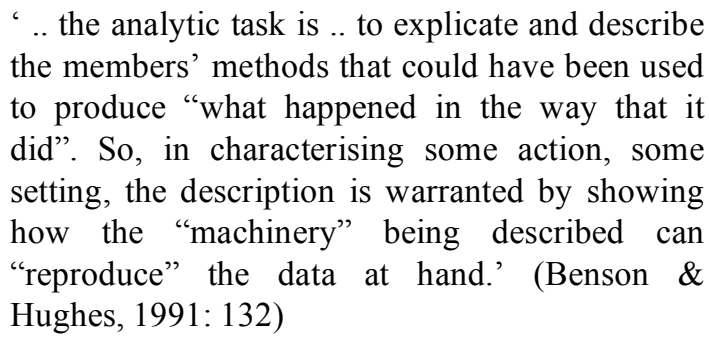

'.. the analytic task is .. to explicate and describe the members' methods that could have been used to produce "what happened in the way that it did". So, in characterising some action, some setting, the description is warranted by showing how the "machinery" being described can "reproduce" the data at hand.' (Benson \& Hughes, 1991: 132)

Thus, the ethnomethodologist does not seek to explicate patterns per se but the social practices - the cultural machinery as it were in and through the accomplishment of which patterns, structures, processes, and the rest, are produced. That machinery may be explicated on any occasion of analysis in describing how the activity described by the instance could be reproduced in and through the self-same practices that the instance makes observable. In doing this, the researcher not only generates factual knowledge from the data itself - in distinction from coded results and pre-defined categories of analysis - but does so without recourse to the documentary method: biography is not imputed but manifest. As Garfinkel announces:

\footnotetext{
'EM is not in the business of interpreting signs. It is not an interpretive enterprise. Enacted local practices are not texts which symbolize "meanings" or events. They are in detail identical with themselves. The witnessably recurrent details of ordinary everyday practices constitute their own reality. They are studied in their unmediated details not as signed enterprises.' (Garfinkel, 1996: 8).
}

As other researchers have noted (Shapiro, 1994), it is this ability to get hands-on realworld practice that affords EM research considerable purchase in the technology development effort. That purchase consists of abandoning the policies and practices of constructive analysis and producing factual knowledge of a calculable status through the 
explication of the orderly work of the target domain in observable details of the work's lived production. Thus, the work of discovering and producing factual knowledge of a calculable status may be achieved through:

- 'Quick and dirty' and concurrent ethnographic study (Hughes et al., 1994).

a Compiling the ethnographic record so as to be able to produce instances of witnessed activities.

- Assembling instances of discrete activities from the ethnographic record that preserve and display the lived work of witnessed activities.

- Describing and explicating in lived detail the practices in and through which instanced activities may be reproduced.

It might be said that the notion of 'reproduction' furnishes the warrant for EM findings to some large extent. ${ }^{10}$ Insofar as the culture consists of and provides unique practices for its activities' situated reproduction, then instances of those practices provide for the generalisation of findings. Instances afford generalisation in that:

a They capture and preserve the particulars of the witnessed activity - the machinery in and through which the activity is produced and reproduced by any competent member as a demonstrable (not to mention morally and legally) sanctionable feature of their competency

- They thus make visible the practices that any competent member engages in order to get the activity done and done again.

We might add to this that the notion of generalisation has as much to do with trustworthiness and relevance as does with scientific credibility and validity from the point of view of system design. Designers need to know whether EM findings are 'typical' and 'generally applicable' to the target domain and whether or not they may (thus) be relied upon - in other words, they need to be able to trust EM findings. The typicality, general applicability, reliability and trustworthy character of EM findings is furnished in identifying the recurrent social practices in and through which members manage the contingent happenings which constitute setting's daily work as a matter of course. Furthermore and underlying the issue of trust: in making observable the social practices in and through which members produce and manage the setting's daily work EM findings assume their particular and distinctive relevance to design. Structures, processes, patterns, etc., are produced through the socially organised practical actions of browsing, searching, finding retrieving etc. While the studies of constructive analysis unearth structures, processes, and patterns (etc.) - Taylor's classic question-negotiation being a prime example (Taylor, 1968) - they do not display the actual lived work the structure, process or pattern emerges from. System design must support the production of structure and process if the technology development effort is to have any chance of being successful. Yet constructive analysis cannot unearth that work as its policies and practices systematically gloss the work from which structure and process emerge. Thus, the trustworthiness and generalisation of findings relies on their relevance to systems design insofar as findings make observable the work that design must support if effective technology is to be developed. It is EM's ability to make observable the lived work of a setting from which structure and process emerges that warrants trust in and thus generalisation of its findings. The machinery discovered in one library, for example, is neither restricted to the members observed nor that particular library, much as the machinery 'at work' in doing-driving-downthe-freeway is not restricted to the driver observed nor the particular freeway. On the contrary, the machinery is, as we all know, generally applicable otherwise persons could not be trained nor display their competency as drivers anywhere. Thus, in observable details of lived work, instances come to elaborate specific design-problems (i.e. problems to be addressed by design) and specify quality criteria supporting the formulation of designsolutions for interactive information systems (Christensen et al., 1998; Crabtree, to appear).

In summary, the aim of EM research is to observe and describe the phenomena of 'everyday life' independently of the preconceptions of received sociological theories and methods; to be 'led by the phenomena' rather than by the concerns and requirements of a particular sociological standpoint. This involves taking a theoretically unmotivated approach to activities - looking just to see what people are doing, rather than seeking to identify things which are sociologically interesting - thereby dispensing with the conventional sociological preconception that there are numerous things which people are doing which are trivial and thus not worth studying. In this way the false starts, interruptions, digressions, and glitches, 
which are aspects of all activities, are notable features of the phenomena, not so much 'noise' to be eliminated in order to reveal sociologically relevant aspects of the data. The phenomena which are to be investigated are consequently studied in their character as phenomena of everyday life. As everyday occurrences for those who are involved in the activities in question. The investigator is, therefore, seeking to ascertain what the phenomena mean for members, and more importantly, how they are made meaningful witnessably in and as of practice. It is not for the investigator to decide what things are, what matters, what is important, or trivial, but to ascertain how things are made sense of in the ways that they are by those who are doing them. In studies of the kind that ethnomethodologically motivated ethnographers make, the concern is with the depiction of the working sensibility of those under study. Thus, attention is focused - in a way which is otherwise unprecedented in sociological studies of work - on the study of doing the work.

\section{Strand Three: The ethnomethodological approach in practice}

Below we provide some practical examples of EM research. ${ }^{11}$ As such, in furnishing selections from instances of the embodied practices in and through which people make sense and produce information in a university library, we hope to encourage the novice to undertake EM studies of library practice. At the same time, the instances serve to elaborate design-problems relevant to the development of digital libraries.

Here, then, we present three edited selections of the lived work occurring in the library. Full details are available in (Crabtree et al., 1997; Twidale et al., 1997; Crabtree, 1999). The instances from which they are derived cannot be provided in full due to constraints of space. Despite this and a degree of recipient design, we hope these snippets serve to elucidate the ethnomethodological approach to discovery and analysis in practical detail.

\section{1) The physical space and artefact as interpretive gestalt:}

A great deal of search behaviour in the library does not entail Online Public Access Catalogue (OPAC) use at all. The following account describes practices that members engage in, in browsing, searching, and retrieving information from the physical catalogue. Jack is the researcher and Craig, the subject, is a third year undergraduate law student who uses a seminar reading list as a basis for performing the search:

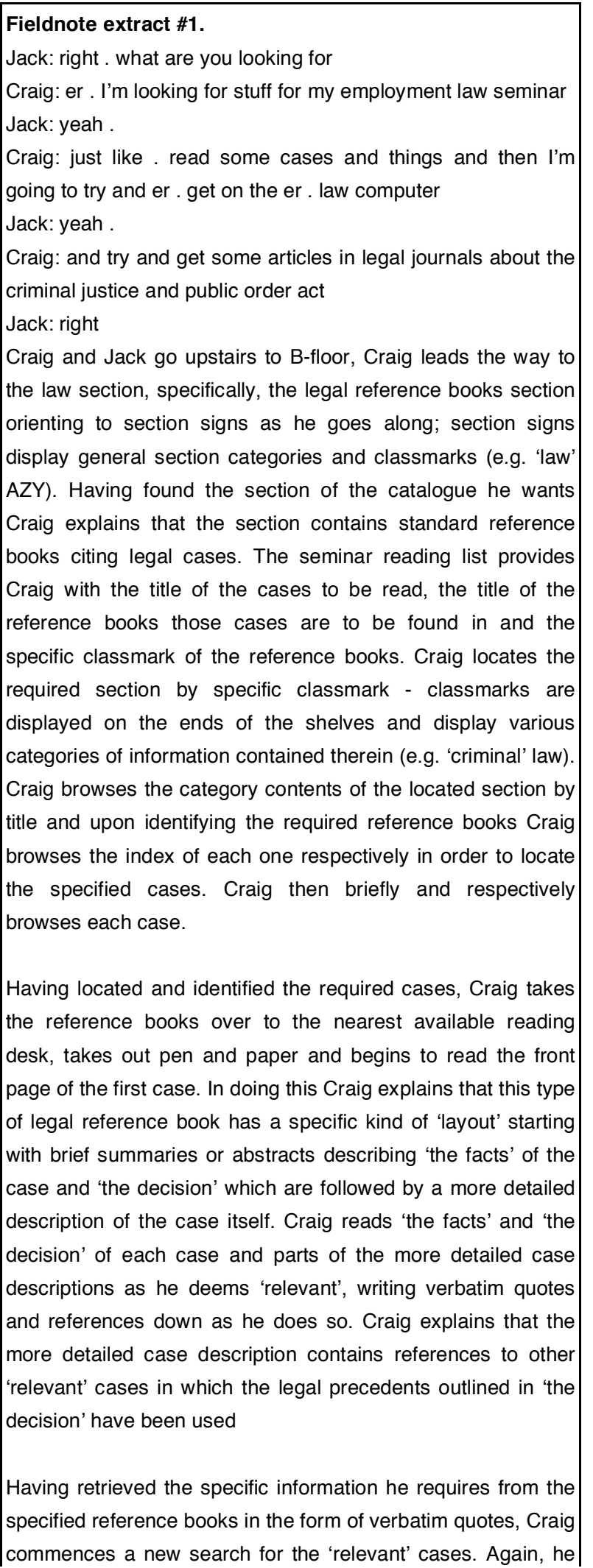

Craig: er . I'm looking for stuff for my employment law seminar Jack: yeah .

going to try and er . get on the er . law computer

Jack: yeah .

Craig: and try and get some articles in legal journals about the criminal justice and public order act

Jack: right

Craig and Jack go upstairs to B-floor, Craig leads the way to the law section, specifically, the legal reference books section orienting to section signs as he goes along; section signs display general section categories and classmarks (e.g. 'law' AZY). Having found the section of the catalogue he wants Craig explains that the section contains standard reference books citing legal cases. The seminar reading list provides Craig with the title of the cases to be read, the title of the reference books those cases are to be found in and the specific classmark of the reference books. Craig locates the required section by specific classmark - classmarks are displayed on the ends of the shelves and display various categories of information contained therein (e.g. 'criminal' law). Craig browses the category contents of the located section by title and upon identifying the required reference books Craig browses the index of each one respectively in order to locate the specified cases. Craig then briefly and respectively browses each case.

Having located and identified the required cases, Craig takes
the reference books over to the nearest available reading
desk, takes out pen and paper and begins to read the front
page of the first case. In doing this Craig explains that this type
of legal reference book has a specific kind of 'layout' starting
with brief summaries or abstracts describing 'the facts' of the
case and 'the decision' which are followed by a more detailed
description of the case itself. Craig reads 'the facts' and 'the
decision' of each case and parts of the more detailed case
descriptions as he deems 'relevant', writing verbatim quotes
and references down as he does so. Craig explains that the
more detailed case description contains references to other
'relevant' cases in which the legal precedents outlined in 'the
decision' have been used
Having retrieved the specific information he requires from the
specified reference books in the form of verbatim quotes, Craig
commences a new search for the 'relevant' cases. Again, he 
does not perform an OPAC search but searches the shelves by classmark and by title. Craig then goes on to the 'law computer' to 'find' some other information.

Analysis of the ethnographic record makes it clear that Craig makes sense of the setting and produces information of relevance through: following signs displaying general classmarks and categories of information; employing specific classmarks and categories in conjunction with a list to locate specific categories of relevance; employing titles to identify items of relevance; employing indexes to locate articles of relevance; employing the structure of articles - their 'layout' (abstracts, titles and sub-titles etc.) to refine the search; selecting and writing down verbatim quotes; selecting and writing down references to other potentially relevant articles from which information is produced in the same ways.

Here we see the reflexive social practices of making sense and producing information in the library. These social practices are embodied, are witnessable, and consist of using general and specific signs furnishing the public means to identify and locate first, general, then specific categories of potential information. It further entails the use of conventional external features of bibliographic items (physical documents) such as titles to locate and identify specific items of potential information; ${ }^{12}$ the use of its conventional internal structures such as indexes, abstracts, titles and sub-titles to refine the search for potential information of relevance; writing down selected text and thus information of relevance; and the use of references to identify other potential sources of information. Signs and other conventions such as books having titles, authors, indexes, titles and sub-titles, references etc. - are intrinsically social. In orienting to and using signs and other conventional features of the catalogue, members make sense of the setting and at the same time (or reflexively in doing so) actively produce information of relevance through engaging in the social practices providing for the witnessed, situated achievement of sense. The point to appreciate here then is that the physical space is a socially ordered space implicated in the production of information in practised ways (Crabtree, 1999).* The organisation of space and practices for its use are not incidental to searching but integral. Thus it is suggested that in the attempt to develop digital libraries, systems design pay attention to the organisation of electronic spaces and seek to develop mechanisms supporting the retrieval of information through spatial interrogation insofar as members find such ways of producing information normal and natural to do (Mariani \& Rodden, 1999).

\section{2) Talking in the library:}

Members frequently encounter problems in finding information of relevance: all too frequently, with its limited categorical choices, OPAC fails to provide (from a members' point of view) a precise and / or flexible enough tool of categorisation. In such cases it is not uncommon for members to seek help - turning to the library's service desk staff is a natural solution. The ethnographic material presented below displays the work involved in 'helping users find what they want' or, as described in the LIS literature and by professional librarians, the work involved in doing 'filtering work'.

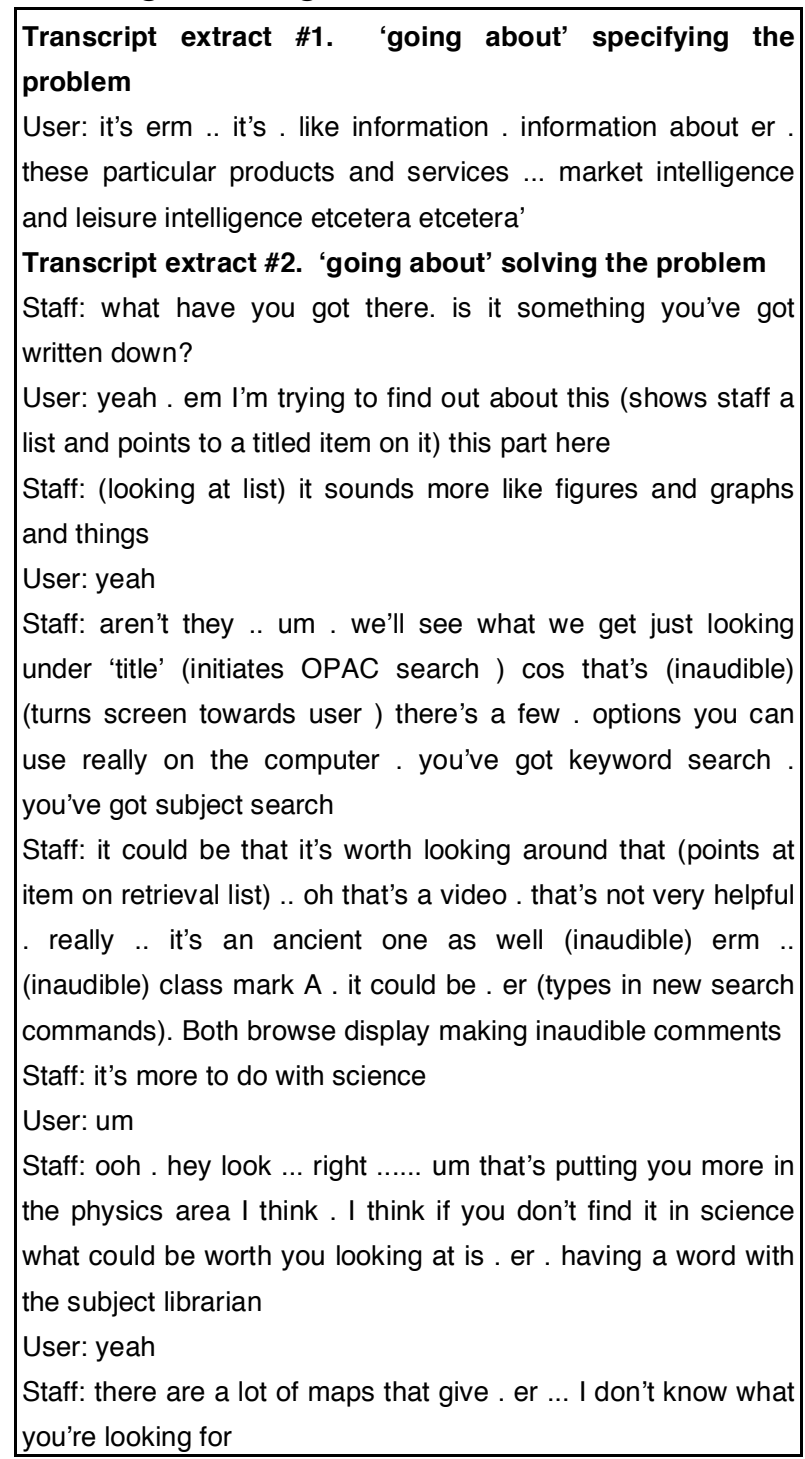


(Taping interrupted - approx. 30 seconds - staff and user browsing a new retrieval list)

Staff: I think we'll send you to the librarian . cos with me browsing like that .. the subject is quite specific

In the above extract, besides staff asking 'what the problem is', the first thing members - staff and user - do is formulate a vague description of the information requirement thus announcing, in a general way, the topic the user is seeking information about - 'it's like information about these particular products and services, market intelligence and leisure intelligence etc.' Having formulated a vague description, staff 'goes about' finding relevant information by using the on-line catalogue's categorical organisation - 'title' for example - to identify an appropriate search category and the user's list to formulate a clearer sense of what is being searched for: 'figures and graphs and things'. Having identified an appropriate search category and formulated a clearer sense of what the user requires - i.e. having formulated a candidate category of solution staff initiates a search on the on-line catalogue and browses retrieved search items in concert with the user. In browsing the retrieved items, staff and user formulate new candidate categories of solution: 'science' for example. Searches on these categories are then used in concert to produce further more 'specific' candidate categories of solution: 'the physics area' for example.

In attempting to solve information requirement problems, users and staff formulate vague descriptions of the topic the user requires information about. In order to produce information satisfying the users' requirement, the vague description needs to be made intelligible in terms of the catalogue's organisation. This may be achieved through the use of lists. ${ }^{13}$ The product of list use is the establishment of requirement 'parameters' or boundaries through the establishment of preliminary information requirement categories: e.g. 'figures and graphs and things'. The formulation of preliminary information requirement categories and, reciprocally, requirement boundaries, provides for the next problem solving action: the formulation of increasingly more specific information requirement categories. Specific information requirement categories are 'worked up' through the use of established candidate categories of solution and the concerted browsing of subsequently retrieved items.
Thus, while not directly solving the user's information requirement in this instance enough knowledge about the kind of information required had been established to warrant referring the user to the subject librarian and further more specific category work - the above segments of talk make visible the social practices that 'filtering work' consists of and relies on for its achievement time and time again. Specifically, the formulation of vague descriptions, the formulation of preliminary information requirement categories of candidate solution, and the formulation of increasingly more specific information requirement categories of candidate solution. Vague descriptions are formulated through the use of lists or the categories of the online catalogue. Categories of the on-line catalogue - 'title', 'journal', 'serial' etc. - are not sufficient to formulate preliminary categories of candidate solution - as they only describe what is or may be required in terms of the catalogue's formal organisation. What is required is some means of retrieving items that relate to - 'sound like' - vague descriptions and preliminary categories of candidate solution. This work currently trades on service desk staffs' knowledge of the library in interpreting the details on lists or otherwise elicited from the user. In establishing preliminary categories of candidate solution, staff and user 'bound' the search and provide for the potential resolution of the problem through the subsequent 'search and browse' formulation of more specific categories of candidate solution. So the work proceeds until a satisfactory outcome is achieved or the search is abandoned. ${ }^{14}$ Thus, in browsing the catalogue within the boundaries of established preliminary categories of candidate solution, 'figures and graphs and things' is worked up into something 'more to do with science' and then something 'more in the physics area': a description of the information requirement that in situ is specific and provides for the next problem solving action: referral of the user to a subject librarian and further specific categorisation work. That members make sense and 'go about' producing information through these practices of categorisation in situations where the specification of information requirements is problematic constitutes, we would suggest, a significant design-problem: how may members' categorisation work be supported (Crabtree $e t$ al., 1997)? ${ }^{15}$ 


\section{3) Finding the order in the machine:}

This next fieldwork extract is taken from a study of CD-ROM users in a University Library and is concerned with one aspect of the sense-making that accompanies this activity: the recognition that using a CD-ROM is fundamentally about the accomplishments involved in using a machine. Thus, one aspect of making sense of things in the production of information which seems especially valuable in the case of CD-ROM users is the ability to discriminate quickly between relevant information and 'noise'. Such expertise becomes important given that whatever their nature, users' errors and failures are always constituted with reference to their interactions with the machine. Consequently when the user does succeed in producing an action, they must then interpret the machine response and utilise this interpretation as the basis for subsequent action:

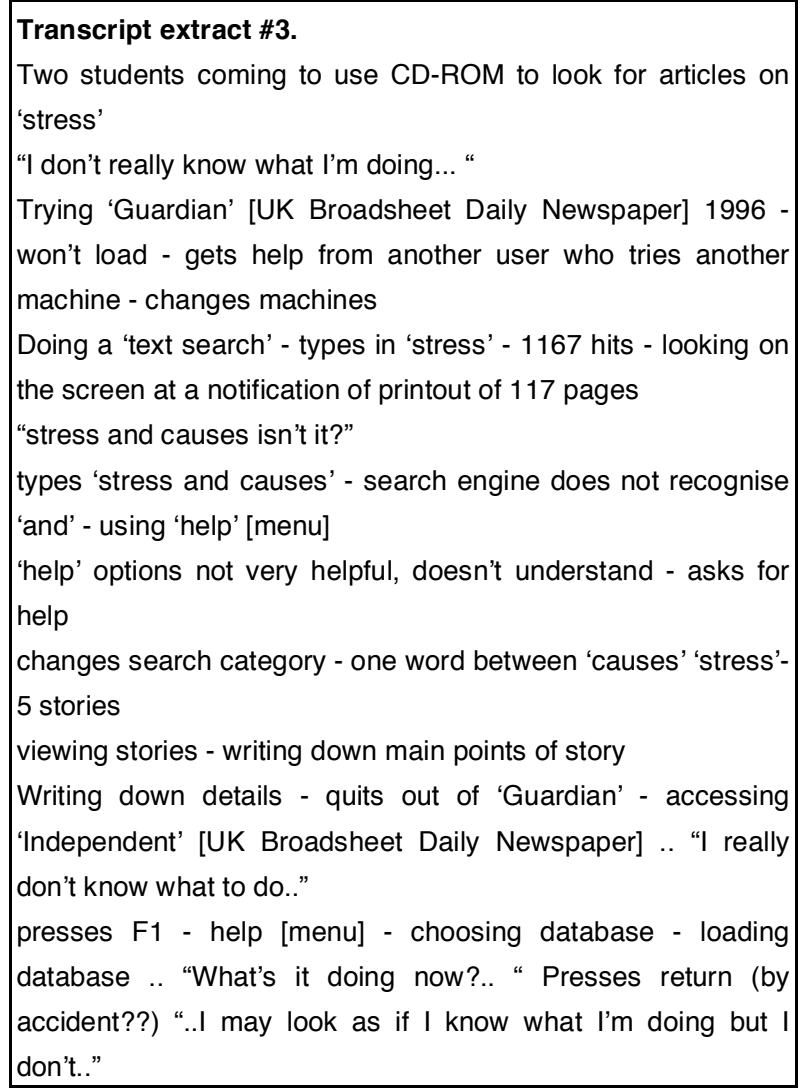

In this extract the users makes a series of selections from menus in an attempt to find articles about stress. The design of the system projects the course of the users' actions as the enactment of various procedures for doing the job. The total sequence of procedures constitutes the 'plan in the machine' which has been implemented as programme. What is important, however, is that user and system each have a different relationship to the design plan 'at work' here (Suchman, 1987). The plan determines the system's behaviour. In order to use the system productively as the plan intended the user is required to find the plan as the product of a set of procedural instructions. A whole series of studies have suggested that people experience considerable difficulties with instructions. In the context of library users this comment is not an indicator of their inveterate stupidity but instead a pointer the problem of following instructions. As Garfinkel (1967) indicates with the term 'irredeemable incompleteness' of instructions, a considerable amount of work is required to carry out instructions. Even when presented with instructions that 'anyone' should be able to understand and follow, practical troubles still arise. Troubles arise in that instructions do not specify the embodied actions required to realise them. Consequently, users are obliged to 'fill in the gap' and it is here that many users (particularly novice users) lose their way as it were. The absence of instructed actions is often fateful to humancomputer interaction. The computer does not 'fill in the gap'. It is in this sense that for the novice user 'thinking can be a mistake' (Carroll \& Mack, 1984) since they characteristically rush to premature and often mistaken conclusions about what has happened, what is happening, what the machine 'meant', what the machine 'is thinking', and so on. The implication: attend to users' strategies for using the machine pay particular attention to the lived work that goes into 'filling in the gap' between instruction and the real-world, real-time achievement of use.

\section{Strand Four: Moving from ethnography to design}

Moving to the second part of this paper, we describe the interpretation and use of ethnographic findings and the difficulties of working with ethnographers from the perspective of information system designers.

\section{The designer's perspective}

As computer scientists it fair to say that we are concerned less with what ethnography is 
than with issues of what we can 'get out of it' to help us build better systems. It is the results, and more specifically, the results in an understandable and interpretable form that are of interest to design. With such a focus, the means by which results are obtained are of lesser interest.

The debate over the relationships between different kinds of ethnography (or between EM and other approaches) as outlined in the first part of the paper might be considered somewhat irrelevant to our concerns as designers, much as the debates about the choice of an object-oriented or procedural approach to the systems design may be deemed an irrelevance to the ethnographers on the design team. Nonetheless, there are issues about the practice of ethnography that it is vital for designers to appreciate if collaboration between the two parties is to work.

More pertinent to a computer scientist, and indeed any researcher considering undertaking a collaborative project with an ethnographer, are the following questions:

- What will I get from them?

․ How do I make use of whatever I get?

- How do we go about collaborating?

- How much time and effort do I have to invest in the collaboration?

- How much about social science do I have to learn?

- How can we make generalisations on the basis of concrete cases?

a Aren't their findings all just obvious?

The essence of the argument for EM research, from the perspective of the system designer, is that if your data collection methods and analysis are based on, or informed by, a particular theory then there is a strong chance that the theory will feed through into the design of the information system. Consequently, the designed system may well reflect the theory of how library users behave rather than the actuality of how they do behave. This mis-match between the designed system and the activities of users can then lead to a wide variety of problems when the new system is implemented (Bowers et al., 1995), including a significant shortfall in expectations (Grudin, 1988) or even system failure (Page et al., 1993).

\section{Design and ethnography}

' ... ethnographies provide both general frameworks and specific analyses of relations among work, technology and organization. Workplace ethnographies have identified new orientations for design: for example, the creation and use of shared artifacts and the structuring of communicative practices.' (Suchman, 1995: 61)

Ethnography as an approach to data collection is not one without problems, many of which have been well documented (Randall et al., 1995) focusing, for example, on such standard qualitative methodological concerns as 'getting in, staying in, getting out' as well as issues of access and gatekeeping, reliability, validity, generalisation, and so on. While these are clearly issues of some, though not overwhelming, interest to EM research, we are nevertheless concerned here with addressing a number of concerns and practical problems that have arisen in our own use of the approach. We do not nominate ethnography as a methodological panacea for the design of better information systems. We recognise the problems which arise with the approach's application to large scale, highly distributed organisations and the incursion of commercial constraints on budgets, time and resources. In particular, approaches such as ethnography must service a number of demands if they are to be widely accepted as an aid to effective systems design. Such caveats, however, apply equally to all other methodological approaches, and it is important not to be too ambitious for any approach, least of all in systems design where new approaches follow one another with monotonous regularity and where design is, at best, a 'satisficing' activity (Shapiro, 1994) in which we do the best we can with what we've got.

The role and value of ethnography in design is a matter of controversy (Anderson, 1994; Plowman et al., 1995). However, if 'the turn to the social' within systems design means that designers should be informed about the social character of work, and it is recognised that ethnography is an important means of gaining such knowledge, then serious attention needs to be given to the variety of ways in which ethnographic studies can be used by designers. Hammersley (1992) suggests:

\footnotetext{
'The purpose of ethnographic analysis is to produce sensitising concepts ... that allow people to see events in new ways. The value (of these concepts) .. is to be judged by others in terms of
} 
how useful they find them.' (Hammersley, 1992:

15)

The purpose of EM research as we have envisaged and practised it to date it is primarily as an aid to design. Ethnography acts as our 'eyes and ears on the ground', informing us as to actual practice, the significance of which would otherwise pass by unnoticed. The role of ethnography in design that has developed in our own studies can be stated in terms of its ability to convey a concrete sense of the real-world aspects of a setting: to see activities as social actions embedded within a socially organised domain accomplished in and through the day-to-day activities of its inhabitants, and to convey this information to designers. Such an approach focuses upon and documents the very activities which designers are concerned to understand, analyse and reconstruct. It is the ability of ethnography to describe a social setting as it is perceived from the point of view of 'users' that underpins its appeal to designers. Ethnography is, consequently, extremely valuable in identifying the exceptions, contradictions and contingencies of work activities which are real conditions of the setting but which will not (usually) figure in official or formal representations.

There may be a case made for ethnography (or sociology more generally) having a more far reaching impact upon design (Hirschheim \& Klein, 1989; Shapiro, 1993). Nevertheless, our policy has always been that it is for designers to draw design conclusions from the results of ethnography. This is not to suggest that ethnographers should not be involved in design - only that questions concerning 'just what' to build are down to designers. As noted earlier, ethnographies role is one of identifying design-problems as seen from the point of view of parties-doing-the-work. 'Just what' such issues amount to for design cannot simply be 'read off' the ethnographic record. Thus, the integration of ethnographic findings into design is achieved through the collaboration of designers and ethnographers. As Button and Dourish (1996) suggest, such collaborations can take a variety of forms: learning from the ethnomethodologist (through their 'stories' of everyday life - of work in the library, say); learning from the ethnomethodological account (of the various activities of users and staff in the library); and learning from ethnomethodology itself (looking, for example, at the kinds of questions raised by Button and Dourish (e.g. "what are the implications of the operation and use of member categorisations for questions of individuality and grouping in software systems?"). There is nothing particularly radical in this; the kinds of changes to design which will result from our approach are intended to have an incremental rather than a comprehensively transformative effect. Fieldwork is concerned with adequately and accurately portraying social settings, and the activities which occur within them. Although oriented towards design, such work should be done independently of design preconceptions. Ethnography's concern is with the preconceptions and activities of those who inhabit the setting. Through such an undertaking, ethnography provides a sanity or reality check of the designer's preconceptions; to ascertain whether the realities of a given setting conform to the ideas of the designer. There is, thus, a basic tension between the designer's and the fieldworker's roles, but this is a positive feature, something which is important to, and essential for, good design. A tension that serves to highlight the difference between good abstract design-solutions and good practical design-solutions.

\section{Problems of interdisciplinary work}

It is important to acknowledge the difficulties that arise in this form of interdisciplinary collaboration. They are only to be expected. Firstly, we are attempting to make the transition from analysis to synthesis - an enduring problem. Even within the confines of computer science this is not easy. More significantly, ethnography and computer science involve two very different academic traditions with some significant differences that need to be appreciated if they are to be overcome in the course of accomplishing interdisciplinary work. We consider aspects of the problems of interdisciplinary work below and ways in which they may be bridged in learning to work together. In essence, interdisciplinarity requires a willingness to devote considerable time to the process of getting to know each other's way of working. We do not have a high-speed solution to offer.

\section{Language and communication}

Inevitably there will be a difference in terminology. Collaboration consists of a continual alertness to uncover cases both of using different words to mean roughly the 
same idea, and terms that are used in completely different ways. Both cases can lead to substantial misunderstanding. Particularly notorious examples of the latter are the meanings of the words 'model', 'semantics', 'method', and 'abstraction'. The question arises of how much of the language of 'the other side' it is necessary to learn in order to communicate effectively (Bradley \& Sutton, 1993). Part of the answer is just to be sensitive to when one is losing the audience, and be willing to be interrupted and to try explaining a matter in less technical language.

One method of achieving effective communication between ethnographers and designers is to 'trade in' stories. This approach emerged in the course of conducting design discussions. The ethnographers told stories to elucidate their findings, thereby recounting the details of instances that embodied a significant set of practical issues. It is interesting to note that an analogous approach is finding favour within computer science in the form of scenario-based design (Carroll, 1995). In both cases, the telling of stories can serve to concretise the issues and focus discussion on actual real-world problems and how technological possibilities could help or hinder their solution. The ethnographers' stories allow us to construct scenarios elaborating hypothetical systems functionalities and their operations within the context of the stories told. These hypothetical solutions are put to the ethnographers as potential solutions to the problems that their story has raised and they are asked for comment. This may yield an elaboration of the current story or the provision of another one to illustrate why the proposed hypothetical technological solution is likely to help or not to help, leading to a revision of respecification of the design scenario. This back and forth scenario tweaking, accompanied by the supply of further stories or elaboration of existing stories, permits design activity without the use of too much technical language.

A key issue in learning to work with ethnographers is in understanding that they may not merely use a different technical vocabulary but also have a different orientation and thus attitude towards issues of design. Again, although we will examine the case of collaboration between systems designers from the perspective of computer science and ethnomethodologically motivated ethnographers, the point applies as much to collaboration between EM ethnographers and a researcher from theoretically informed social sciences. Compounding the problem of communication for computer scientists is that consideration of 'worldviews', to use a somewhat provocative phrase, can be rather alien. Self-reflection is not a conventional academic activity in computer science. Albeit somewhat crudely, we will attempt to outline what we take to be some of the central issues here. They are in danger of being reduced to stereotypes and the individual, although conceding a grain of truth in the issues, may deny that the description actually applies to him or her. Nevertheless, an appreciation of these stereotypes can help in gaining a better understanding of the views, actions and interests of the 'other' side. The different 'worldviews' at work lead to a concentration on certain aspects of collaboration as being of particular interest and demand a certain sensitivity to particular issues

\section{The practical attitude of ethnographers}

The earlier parts of this paper have endeavoured to elaborate this 'worldview' (i.e. a practical set of relevances constituting a distinct practical attitude). Ethnography is directed toward detail, toward the production of a rich and concrete portrayal of the situation, rather than an abstract and spare one. Abstraction and simplification are characteristically resisted, for it is the disposition of ethnography to insist upon citing items, incidents, activities or practices within their context, to emphasise that their meaning, or sense, is only properly comprehended within the appropriate sociocultural situation. To see things 'right' is to see them in their context, and to portray them in an abstract and spare way is to divest them of their sense, to distort the understanding of their role. There is, and rightly so, a resistance to simplification. Thus, the product of such studies involves the extensive use of discursive text which explicates and elaborates examples drawn from the field. Ethnography in an ethnomethodological mode is about understanding the world as it is produced by participants in situ and in action. As such, it is non-judgmental - EM tells you what is, not what ought to be. It does not seek to construct theories that explain behaviour but rather, seeks to make behaviour theorised about but glossed over, observable in practised real-world detail.

The practical attitude of computer scientists 
Computer science in terms of systems design is an aspect of engineering. It is about trying to construct programs and get them to work. It is about identifying problems and fixing them, both in the workplace by the development and introduction of new systems, and in the process of getting these systems to work (by debugging, for example). We can see computer science as being in the modernist, optimist paradigm - everything has a technological fix, and the problems introduced by technology can be solved by more technology. Since the 1960s a growing understanding of the 'software crisis' has led to the development of software engineering. This tries to tackle a range of related issues including how to generate code more efficiently and how to ensure that the programs created do in fact yield improvements in efficiency when deployed. This leads to a concern to better understand what the system to be designed needs to do the process of requirements capture. It was in addressing this problem that it was first considered that ethnography might make an important contribution. The process of systems design is about abstraction and simplification - the building of models and the concentration on data flows that can be modelled and manipulated. Thus the analysis that precedes synthesis is necessarily reductionist. Design often occurs with the supply of a (supposedly) precise description of the problem and what is to be built. Design is about abstraction and complexity, and the designer is characteristically in search of ways of simplifying the complexity of the design situation, often by means of abstractions which will delineate critical features of that situation and of the designproblem it presents. The designer wishes to find mechanisms which will quickly and succinctly convey the aspects of a design that are key to meeting the problem at hand.

\section{Comparison of practical attitudes}

This elaboration of practical relevances helps to illustrate why the two groups experience difficulties in working together and why they may frequently talk at crosspurposes. It also reveals why it is important that they should work together given the complementarities of the two approaches. Numerous computing projects have failed even though the resultant program did precisely what it was specified to do. The cause of the failure? The specification was in error because it over-simplified the work activity in classic computing reductionist style, thereby ignoring crucial aspects of the activity that should not be abstracted away. It is the hope that ethnography will help in serving to warn about what should not be ignored, while not insisting that everything is important.

There is the danger that the computer scientists will expect the ethnographers to tell them what to build. Arguably, that would be to misunderstand the purpose of ethnography, but at the same time, design does require ethnographers to participate in the process of judging and recommending, something that they may find alien. It is important that the ethnographers are prepared to commit to the making of design decisions.

Although ethnographers generate a great deal of data (and even this is a distillation of the huge amounts collected in the field), the resulting reports should not be judged to be the 'result' of an ethnographic study. Rather the result emerges from the ongoing design dialogue with the ethnographers including their selection of illustrative cases to address the design questions and hypotheticals that the designers raise. We would claim that it would be extremely difficult to do an effective design based solely on a written report of an ethnographic study - too much is lost. To a computer scientist, the design dialogue with the ethnographer is itself a form of requirements capture, or knowledge acquisition. Ultimately, we would concur with Rogers and Bellotti (1997):

\footnotetext{
'... ethnography is most likely to show its value in being expounded within an ongoing dialogue between collaborating ethnographers and designers about observations and understandings derived from field studies, together with interesting capabilities of new technology configurations.'
}

\section{Undertaking design}

We have reported on the design implications of the library studies elsewhere (Crabtree 1999; Crabtree et al., 1997; Twidale et al., 1997). For the methodological purposes of this paper, we wish to consider more general design issues implicated in the use of ethnography. The process of using ethnography to inform systems design is difficult because of the differences between the cultures of computing and ethnography. These difficulties can be overcome however. 
Ethnography offers powerful insights into existing work practice that can be used to inform systems design (Button \& Harper, 1996). 'Informing design' does not, to reiterate the point, consist of making explicit recommendations as to what to build, but of making designers aware of effective arrangements of work that may be in danger of being ignored in the envisaged redesign (and which may, therefore, lead to rejection of the system).

A persistent theme of the descriptions of work that ethnography provides is how people cope with systems under constraints of time and available information on how to proceed. There is much 'muddling through' and coping behaviour (much "making do and getting on with what we've got"), using the available functionalities in a manner that an expert would consider sub-optimal, and using functionalities in ingenious, unintended ways to achieve the desired ends. It is all too easy as a computer scientist to react to these stories by declaring "but they are doing it all wrong, if only they would do XYZ they could get a better result in half the time - clearly what is needed is a user education programme". In the case of library information systems, we would claim that an equivalent initial reaction from a librarian would involve horror at the inefficiency of the search strategies being ordinarily or naturally employed by users and a declaration that the problem can be solved by more reference librarians available or a suitable course of bibliographic instruction. Although the reactions by the computer scientists and librarian alike are understandable, and the solutions proposed might work, we believe that there is an alternative.

The ethnographic descriptions and resulting reactions, not surprisingly, have parallels with work in the early days of HCI where systems designers were shown videotape of regular users struggling to understand the computer interface the team had developed. Much of the effort in $\mathrm{HCI}$, especially in commercial systems development contexts, was to sensitise designers to the brute fact that they were designing for users who did not have a degree in computer science and did not find computers inherently fun and interesting to explore. Thus, designing a system, and especially an interface, so that it could be used by the designers and their friends was inadvisable.
In a similar way, ethnography can serve to make us aware of the differences between end-users and those involved in the development process, and to help us consider how to design for the former rather than for ourselves. We would point out that this may mean the design of systems with features that a computer scientist may find clumsy or longwinded (as with some graphical interfaces). In the context of library systems design it may also mean the design of systems with features that a librarian may find clumsy or longwinded. We may, in effect, be obliged to design specifically for 'perpetual novices' (Borgman, 1996). Whatever way we construe matters here, the lesson of ethnography is to design systems for people in light of what they actually $d o$, not what they ought to do. As design inevitably involves compromise, that may mean downgrading the prominence of features that an expert would find more useful. Of course, if resources permit, there is always the possibility of adding unobtrusive features or even an entire interface for the 'power user', but the EM approach emphasises this as being a secondary rather than a primary concern. This re-prioritisation is easy to state, but harder to act on. One produces and delivers systems for clients, and library patrons do not buy library interfaces, libraries do. Thus, the lessons of ethnography will need to be sold to the commissioning client (quite possibly a skilled librarian) as well as to the systems developer. ${ }^{16}$

\section{Conclusion}

In many senses the point of this paper has been to bring a methodological awareness to bear on ethnographic study. The methodological distinctions and guidelines we have presented here may be applied to the study of any setting whether one is involved in systems design or not. Insofar as we are concerned with systems design, issues of methodology inevitably revolve around issues of relevance - after all aren't EM findings "just obvious"? Well yes! Of course they are insofar as they come as little surprise to members who perform the daily work of the setting but not to researchers who have to develop technological support for that work. Finding out what the setting's daily work consists of, what the practical problems of work are, what members do in order to solve those practical problems - really, not hypothetically - are central problems to be addressed on any occasion of design. As such, 
the practical problem faced by design is one of developing means of 'going about' discovering the real work of the setting on any occasion of design. Over recent years, ethnography has emerged as one such means. Immersing a researcher in the setting is not an answer in-itself however, insofar as the product of that immersion - the ethnographic record - is subjected to the policies and practices of constructive analysis which systematically gloss and obscure the realworld work of the setting. More than that, there is a danger in developing systems to meet criteria of the theories used to structure ethnographic data with the consequences that design reflects the theory rather than actual practice.

In treating ethnographic study methodologically - rather than theoretically the EM approach to ethnographic study offers a remedy to the limitations of constructive analysis. Thus, while not offering the 'silver bullet' to problems of design, we recommend that the ethnographer produce instances of the discrete activities a setting's daily work consists of and that analysis is performed through explicating the actions and practices instances make observable. This stands in contrast to imposing external analytic frameworks and explanatory constructs on the ethnographic record. In describing the situated actions and practices persons engage in, in order to get the work done, the ethnographer elaborates concrete designproblems and specifies quality criteria supporting the formulation of designsolutions for interactive information systems. The warrant for the design-problems and quality criteria emergent from the design dialogue with ethnomethodologically motivated ethnographers is provided by practice itself. Instances portray the recurrent ways in which discrete activities are produced, performed, and accomplished by members time and time again. Portray, that is, the work practices in and through which unique activities 'get done' by any competent member. If design is to successfully restructure activities and implement new processes of information production (and use), then designers must provide for the performance of the work from which structure and process emerge. How else could information systems design, indeed any form of design, proceed?

\section{Acknowledgements}

The studies described here were funded by the British Library Research and Innovation Centre as part of the project Investigation of Collaborative Browsing and its Implications for System Design.

\section{References}

Ackroyd, F \& Hughes, J.A. (1992) Data Collection in Context, London: Longman.

Anderson, R.J. (1994) Representations and requirements: the value of ethnography in system design, Human-Computer Interaction, 9 (1), 151182.

Bates, M.J. (1989) The design of browsing and berrypicking techniques for the online search interface, Online Review, 13 (5), 408-425.

Benson, D. \& Hughes, J.A. (1991) Method: evidence and inference, Ethnomethodology and the human sciences (ed. Button, G.), 109-136, Cambridge: Cambridge University Press.

Blomberg, J. Suchman, L., Trigg, R. (1994) Reflections on a work-oriented design project, Proceedings of the 1994 Participatory Design Conference, 99-109, Chapel Hill, North Carolina: Computer Professionals for Social Responsibility.

Blumer, H. (1969) The Sociological Implications of the Thought of George Herbert Mead, Symbolic Interactionism: Perspective and Method, 61-77, Berkeley: University of California Press.

Blythin, S., Rouncefield, M., Hughes, J.A. (1997) Never mind the ethno' stuff, what does all this mean and what do we do now: ethnography in the commercial world, Interactions, 4 (3), 38-47.

Bogdan, R. \& Taylor, S.J. (1975) An introduction to qualitative research methods: a phenomenological approach to the social sciences, New York: Wiley.

Borgman, C. L. (1996) Why are online catalogs still hard to use? Journal of the American Society for Information Science, 47 (7), 493-503.

Bowers, J., Button, G., Sharrock, W. (1995) Workflow from within and without, Proceedings of the Fourth European Conference on Computer Supported Cooperative Work, 309-324, Stockholm, Sweden: Kluwer Academic Publishers.

Bradley, J. (1993) Methodological issues and practices in qualitative research, Library Quarterly, 63 (4), 431-449.

Bradley, J. \& Sutton B. (1993) Reframing the paradigm debate, Library Quarterly, 63 (4), 405410.

Button, G. (ed.) (1991) Ethnomethodology and the Human Sciences, Cambridge: Cambridge University Press.

Button, G. (ed.) (1992) Technology and Working Order: Studies of Work, Interaction and Technology, London: Routledge.

Button, G. \& Dourish P. (1996) Technomethodology: paradoxes and possibilities, Proceedings of the 1996 
ACM Conference on Human Factors and Computing, 19-26, Vancouver, Canada: ACM Press.

Button, G. \& Harper, R. (1996) The relevance of 'work-practice' for design, Computer Supported Cooperative work: The Journal of Collaborative Computing, vol. 4, 263-280.

Carroll, J.M. (ed.) (1995) Scenario-based Design: Envisioning Technology in Use, New York: John Wiley.

Carroll, J.M. \& Mack, R.L. (1984) Learning to use a word-processor, Human factors in computer systems (eds. Thomas, J.C \& Schneider, M.L.), 13-51, Norwood, New Jersey: Ablex.

Christensen, M., Crabtree, A., Damm, H.D., Hansen, K.M., Madsen, O.L., Marqvardsen, P., Mogensen, P., Sandvad, E., Sloth, L., \& Thomsen, M. (1998) The M.A.D. experience: Multiperspective Application Development in evolutionary prototyping. Proceedings of the Twelfth European Conference on Object-Oriented Programming, 1441, Brussels, Belgium: Springer.

Crabtree, A., Twidale, M.B., O’Brien, J. \& Nichols, D.M. (1997) Talking in the library: implications for the design of digital libraries, Proceedings of the $2^{\text {nd }}$ ACM International Conference on Digital Libraries, 221-228, Philadelphia: ACM Press.

Crabtree, A. (1998) Ethnography in Participatory Design, Proceedings of the 1998 Participatory Design Conference, 93-105, Seattle: Computer Professionals for Social Responsibility.

Crabtree, A. (1999) Searching as a Socially Organised Achievement in the Library, eSCAPE Deliverable 4.1 The Abstract Library Demonstrator, Esprit Long Term Research Project 25377, Lancaster University: Computing Department.

Crabtree, A. (1999) Remarks on the Social Organisation of Space and Place, eSCAPE Working Paper, Lancaster University: Computing Department.

Crabtree, A. (to appear) Talking work: languagegames, organisations and computer supported cooperative work, Computer Supported Cooperative Work: The Journal of Collaborative Computing.

Dervin, B. (1992) From the mind's eye of the user: the sense-making qualitative-quantitative methodology, Qualitative research in information management (eds. Glazier, J.D. \& Powell, R.R.), 61-84, Englewood: Libraries Unlimited.

Dilthey, W. (1988) Introduction to the human sciences: an attempt to lay a foundation for the study of society and history (trans. Betanzos, R.J), London: Harvester Wheatsheaf.

Elion, S. (1968) Taxonomy of communications, Administrative Science Quarterly, vol. 13, 266-288.

Fielding N. (1994) Ethnography, Research in social life (ed. Gilbert, N.), 154-171, London: Sage.

Fischer, G. \& Reeves, B. (1992) Beyond intelligent interfaces: exploring analyzing and creating success models of cooperative problem solving, Applied Intelligence, 1 (4), 311-332.
Frohmann, B. (1992) The power of images, Journal of Documentation, 48 (4), 365-386.

Garfinkel, H. (1967) Studies in Ethnomethodology, Englewood Cliffs, New Jersey: Prentice-Hall.

Garfinkel, H. (1996) Ethnomethodology's Programme, Social Psychology Quarterly, 59 (1), 5-21.

Giddens, A. (1984) The constitution of society: outline of the theory of structuration, Berkeley: University of California Press.

Grudin, J. (1988) Why CSCW applications fail: problems in the design and evaluation of Organisational Interfaces, Proceedings of the 1988 ACM Conference on Computer Supported Cooperative Work, 85-93, Portland, Oregon: ACM Press.

Hammersley, M. (1992) What's wrong with ethnography? Methodological explorations, London: Routledge.

Hirschheim, R. \& Klein, H.K. (1989) Four paradigms of information-systems development, Communications of the ACM, 32 (10), 1199-1216.

Hughes, J.A, King, V., Randall, D., Sharrock, W. (1993) Ethnography for system design: a guide, COMIC Working Paper, Computing Department, Lancaster University, United Kingdom

Hughes, J.A, King, V., Rodden, T., Andersen, H. (1994) Moving out of the control room: ethnography in system design, Proceedings of the 1994 ACM Conference on Computer Supported Cooperative Work, 429-438, Chapel Hill, North Carolina: ACM Press.

Hughes, J.A. \& Sharrock, W. (1997) The philosophy of social research, London: Longman.

Hymes, D. (1986) Models of the interaction of language and social life, Directions in sociolinguistics: the ethnography of communication (eds. Gumperz, J.D. \& Hymes, D.) , 35-71, New York: Basil Blackwell.

Kuhlthau, C.C. (1993) Seeking meaning: a process approach to library and information services. Norwood, New Jersey: Ablex.

Lamont, N. (1995) The Computer in the Workplace: Cognitive and Sociological Modelling of Users, Ph.D. thesis, Faculty of Social and Economic Studies, University of Manchester, UK: Department of Sociology.

Livingstone, E. (1997) The Ordinary Society, unpublished manuscript, UCLA: Sociology Department.

Mariani, J. \& Rodden, T. (1999) eSCAPE Deliverable 4.1 The Abstract Library Demonstrator, Esprit Long Term Research Project 25377, Lancaster University: Computing Department.

Mellon, C. A. (1990) Naturalistic inquiry for library science, Westport: Greenwood Press.

Nardi, B.A. \& O’Day, V. (1996) Intelligent agents: what we learned at the library, Libri, 46 (2), 59-88.

O’Day, V. \& Jeffries, R. (1993) Orienteering in an information landscape: how information seekers get from here to there, Proceedings of INTERCHI'93, 438-445, Amsterdam: ACM Press. 
Packer, M.J. \& Addison, R.B. (1989) Entering the circle: hermeneutic investigation in psychology, Albany: State University of New York Press.

Page, D., Williams, P. \& Boyd, D. (1993) Report of the Inquiry into the London Ambulance Service, SouthWest Thames Regional Health Authority, London: Communications Directorate.

Plowman, L., Rogers, Y., Ramage, M. (1995) What are workplace studies for? Proceedings of the Fourth European Conference on Computer Supported Cooperative Work, 309-324, Stockholm: Kluwer Academic Publishers.

Randall, D., Rouncefield, M., Hughes, J.A. (1995) Chalk and cheese: BPR and EthnomethodologicallyInformed Ethnography in CSCW, Proceedings of the Fourth European Conference on Computer Supported Cooperative Work, 325-340, Stockholm: Kluwer Academic Publishers.

Rogers, Y. \& Bellotti, V. (1997) Grounding blue-sky research: how can ethnography help? Interactions, 4 (3), 58-63.

Rouncefield, M., Hughes, J.A., Rodden, T., Viller, S. (1994) Working with "Constant Interruption": CSCW and the Small Office, Proceedings of the 1994 ACM Conference on Computer Supported Cooperative Work, 275-286, Chapel Hill, North Carolina: ACM Press.

Ryle, G. (1971) The Thinking of Thoughts, University Lectures No. 18, Canada: University of Saskatchewan.

Sacks, H. (1963) Sociological Description, Berkeley Journal of Sociology, vol. 8, 1-16.

Sandstrom, A. R. \& Sandstrom, P. E. (1995) The use and misuse of anthropological methods in library and information science research, Library Quarterly, 65 (2), 161-199.

Shapiro, D. (1993) Interdisciplinary Design: Some Possibilities, Proceedings of the 16th Information Systems Research Seminar in Scandinavia, 15-27, University of Copenhagen: Computer Science Department.

Shapiro, D. (1994) The limits of ethnography: combining social sciences for CSCW, Proceedings of the 1994 Conference on Computer Supported Cooperative Work, 417-428, Chapel Hill, North Carolina: ACM Press.

Sharrock, W. \& Button, G. (1991) The social actor: social action in 'real time', Ethnomethodology and the human sciences (ed. Button, G.), 137-175, Cambridge: Cambridge University Press.

Solomon, P. $\left(1997^{\mathrm{a}}\right)$ Discovering information behaviour in sense making: time and timing, Journal of the American Society for Information Science, 48 (12), 1097-1108.

Solomon, P. $\left(1997^{\mathrm{b}}\right)$ Discovering information behaviour in sense making: the social, Journal of the American Society for Information Science, 48 (12), 1109-1126.

Solomon, P. $\left(1997^{\mathrm{c}}\right)$ Discovering information behaviour in sense making: the person, Journal of the American Society for Information Science, 48 (12), 1127-1138.

Squires, D. (1997) Exploring the use of interactive information systems in academic research: borrowing from the ethnographic tradition, Education for Information, 15 (4), 323-330.

Suchman, L. (1983) Office procedures as practical action: models of work and system design, $A C M$ Transactions on Office Information Systems, 1 (4), 320-328.

Suchman, L. (1987) Plans and Situated Actions: The Problem of Human-Machine Communication, Cambridge: Cambridge University Press.

Suchman, L. (1995) Making work visible, Communications of the ACM, 38 (9) 46-61.

Taylor, R. S. (1968) Question-negotiation and information seeking in libraries, College \& Research Libraries, 29 (3), 178-194.

Tesch, R. (1990) Qualitative research: analysis, types and software tools, New York: Farmer.

Twidale, M.B., Chaplin, D., Crabtree, A., Nichols, D.M., O’Brien, J. \& Rouncefield, M. (1997) Collaboration in Physical and Digital Libraries, British Library Research and Innovation Centre Report No. 64.

Weick, K.E. (1995) Sensemaking in organisations, Thousand Oaks, California: Sage.

Winch, P. (1958). The idea of a social science, London: Routledge \& Kegan Paul.

Zeitlyn, D., Bex J. \& David, M. (1997) Making sense of on-line information, Proceedings of the $4^{\text {th }}$ International Conference on Electronic Library and Visual Information Research, 219-227, Milton Keynes: Aslib.

Zimmerman, D. \& Pollner, M. (1973) The everyday world as phenomenon, Understanding everyday life: towards the reconstruction of sociological knowledge (ed. Douglas, J.D.), 80-103, Chicago: Aldine.

Zimmerman, D. \& Wieder, D.L. (1973) Ethnomethodology and the Problem of Order. Understanding everyday life: towards the reconstruction of sociological knowledge (ed. Douglas, J.D.), 285-298, Chicago: Aldine. 


\section{Notes}

${ }^{1}$ One of the reviewers suggested that we should rewrite the paper so as to account for interdisciplinary work in terms of a 'seamless collaboration'. While there is much to the point, what we wish to elucidate here are some of the practical problems involved, and resolved, in making that collaboration seamless. It almost goes without saying that as practitioners we take these to be ubiquitous problems. Hence our attention to them.

${ }^{2}$ Ethnography has a long history in social research see Ackroyd and Hughes (1992); Hughes et al. (1993); Hughes et al. (1994); for example.

${ }^{3}$ A curious feature of abstract generalisations in social science is that unlike abstract generalisations in natural science or mathematics, the generalised features of individual cases cannot be rigorously recovered. As Sacks (1963: 93) points out, this curiosity is a consequence of social science practices of description which systematically gloss or obscure and remove the particularities of the case whereas the descriptions of natural science and mathematics 'retain the features of the particular cases: [thus] given the generalisation one can always recapture the particular object.' The issue is a central one and will be addressed in due course.

${ }^{4}$ Specifically, and to reiterate the point, of the practices in and through which the ethnographic record is treated: of codification, classification, documentary interpretation, analysis of patterns through the use of pre-defined analytic frameworks, and the achievement of rigorous status and professional intelligibility through the use of master narratives.

${ }^{5}$ This is not to say that the findings of constructive analysis are necessarily mistaken or just plain wrong. Rather, insofar as they do produce factual knowledge of a calculable status - i.e. knowledge that through the rules and procedures governing its production is construed as generalisable and warrants inference and action (the implementation of social policy or specification of requirements in system design say) then it is through practices other than those officially sanctioned by the scientific community. One such practice is the documentary method which is formally eschewed. Logico-empirical methods are advocated instead but, as Garfinkel's (1967) pioneering work in the field clearly demonstrates, taking the documentary method out of the loop has proved to be a recalcitrant and central methodological problem in social research. Formulating a solution to this problem is in many respects the methodological theme of this paper. That is to say, we are seeking to develop means of producing factual knowledge of a calculable status that emerges from the phenomena itself on any occasion of inquiry as opposed to documentary practices of inference based on the interpretation of coded results.

${ }^{6}$ This is not to ridicule or ironicise constructive analysis. Its achievements are unquestionable. However, for practical purposes of social research and system design alike, we want to know 'what more' there is to the making of sense and production of information, and 'what more' we have to do in order to find that out? Insofar as the practices of constructive analysis prevent us from answering that question, we seek alternatives (Garfinkel, 1996).

${ }^{7}$ The use of 'doing' in EM studies is designed to emphasise the practically achieved and accomplished character of activities. Thus one might speak of 'doingreading-a-book', 'doing-driving-down-the-freeway' or 'doing-writing-a-paper' for example.

${ }^{8} \mathrm{EM}$ is not in the business of explanation as that notion is understood in the social sciences. The business of explanation - of abstracting from witnessed appearances and constructing master narratives or models according to the rules and procedures governing the production of factual knowledge of a calculable status - trades on, offers accounts of and about, rather than makes visible, the social practices in and through which members produce and manage the daily affairs of a setting. Thus EM eschews explanation and urges the researcher to treat practice as a topic of inquiry through and through rather than a resource for building explanatory constructs (Zimmerman \& Pollner, 1973).

${ }^{9}$ The insistence that EM's findings not be read and thereby treated from a theoretical stance is, as Sharrock and Button (1991: 139) point out, 'invariably disattended, thus allowing its arguments and studies to be read as straightforward exercises in sociological theorising, directed toward constructing a sociological apparatus and, inevitably on this reading, found to be inadequate for the purpose.' In light of these remarks, we urge the reader not to 'disattend'; we offer no theory or model of information retrieval - our studies should not be read or treated as explanations - but as thick descriptions making observable the situated actions and practices in and through which members make sense and produce (in this case) information in the library.

10 No matter what idiosyncratic doings any individual might engage in, in the course of performing a distinct activity, the activity itself consists of a unique family of practices which provides for its production (but not necessarily its successful accomplishment) on any occasion of its performance. By way of example: consider doing-driving-down-the-freeway. Consider how un-individual the production of that activity is; how everybody 'goes on' in the same kind of ways; how everyone so visibly does the same sort of things in 
order to get the activity done here and now and yet again tomorrow. A study of just a few people over a short period of time on a single freeway can tell us much about freeway driving in general. It would be odd if it didn't, if driving-down-the-freeway was different from place to place and state to state (minor regulations aside). Even though every driver is a unique individual, they are not unique drivers otherwise driving would nearly always be fatal.

${ }^{11}$ Unfortunately, as the reviewers of the paper have noted, this takes up a considerable amount of space and may lead to the illusion that the paper is seriously 'imbalanced'. Ethnographic studies are indeed lengthy - that is a fact of life and in such detail, what provides their purchase - we can do no other than apologise to readers who would like a concise account except to say that we believe practical examples to be of great value to those wishing to conduct ethnographic study; much as the distinctions we have drawn between EM and other ethnographic approaches serve to inform those wishing to undertake such inquiries in illuminating the pitfalls of orthodox ethnographic research.

${ }^{12}$ Other ethnographic studies show that we may add 'authors' and loan status - e.g. 'popular' - to this.

${ }^{13}$ Not all users are in possession of a list and further ethnographic studies reveal that service desk staff use the on-line catalogue to elicit the user's knowledge of the topic and thereby formulate categorisable descriptions.

14 Again, further ethnographic studies show that abandoning a search is warranted for service desk staff in the failure to 'work up' and establish further categories of candidate solution - users are usually referred to a section of the catalogue that offers the best potential based on what has been established 'up to now' and are encouraged to return should anything more of relevance thereby come light.

${ }^{15}$ It is interesting to note that the findings from this study at the service desk show very similar activities to those reported by Fischer and Reeves (1992) in their study of help giving in a substantially different context: interactions between customers and sales agents in a hardware store.

${ }^{16}$ The EM approach to ethnographic inquiry can also be used to effect change in an organisation that does not necessarily involve the design of computer systems. For example Blythin et al. (1997) provide recommendations that involve managerial / organisational changes. Such an approach would be equally applicable in a library context. 